\title{
¿QUÉ ES UNA ONTOLOGÍA POLÍTICA?
}

\section{WHAT IS A POLITICAL ONTOLOGY?}

\section{Emmanuel Biset}

Universidad Nacional de Córdoba, Córdoba, Argentina

biseticos@gmail.com

Palabras clave: Ontología, política, posfundacionalismo, deconstrucción.

Keywords: Ontology, politics, postfoundationalism, deconstruction.

Resumen: En este artículo me interesa presentar una definición posible de ontología política. Para ello, comienzo señalando cuáles son los rasgos generales desde los cuales se la define como mero antecedente de la epistemología. Frente a ello, primero, reconstruyo la perspectiva de W. Connolly como antecedente central del uso del término ontología en teoría política. Segundo, sistematizo bajo la expresión "ontologías políticas" ciertos modos en que se trabaja desde el posfundacionalismo el vínculo entre ontología y política. Tercero, bajo la expresión "políticas ontológicas" sistematizo las posiciones que han trabajado el vínculo entre ontología y política desde el giro ontológico en antropología. Por último, recuperando lo analizado, presento una definición de ontología política deconstructiva. El texto tiene, entonces, dos objetivos: por un lado, sistematizar las discusiones en torno al sintagma "ontología política"; por el otro, otorgar una definición específica de la misma.

Abstract: In this paper, I am interested in presenting a definition of "political ontology". To this end, first, I reconstruct W. Connolly's perspective as a central antecedent of the use of the term ontology in political theory. Second, I systematize under the expression "political ontologies" certain ways in which the relation between ontology and politics is worked out from postfoundationalist political thought. Third, under the expression "ontological politics" I systematize the positions that have worked on the relation between ontology and politics since the ontological turn in anthropology. Finally, recovering what has been analyzed, I present a definition of deconstructive political ontology. The text has, then, two objectives: on the one hand, to systematize the discussions around the syntagm "political ontology"; on the other hand, to provide a specific definition of it. 


\section{l.Introducción}

\section{En The Oxford Handbook of Contextual} Political Analysis, editado por R. Goodin y C. Tilly, el primer apartado titulado "Philosohpy Matters" contiene un texto de C. Hay titulado "Political ontology". Me interesa partir de la definición propuesta por Hay porque sintetiza una aproximación general del sentido en el cual una reflexión ontológica puede ser relevante para pensar la política o, en sus términos, para efectuar un análisis político contextual. La pregunta inicial es cómo es posible reunir dos dimensiones que, a priori, parecen antagónicas: la reflexión filosófica más abstracta y la necesidad de contextualizar el análisis político. Para responder a esto, Hay sostiene que los supuestos ontológicos son anteriores a las opciones epistemológicas y metodológicas. Esto significa que los supuestos relativos a la naturaleza de la realidad política conllevan elecciones, muchas veces no explicitadas, que sustentan buena parte de las controversias en el análisis político.

Para explicitar su posición, Hay sostiene que el término ontología ha tenido dos usos generales: por un lado, existe un uso de ontología que refiere a la naturaleza del ser mismo (la pregunta tradicional en este sentido sería por qué existe algo en lugar de nada); por otro lado, existe un uso de ontología que refiere a la naturaleza, la esencia y las características del objeto de una investigación analítica. Para Hay se trata de adoptar esta segunda definición como "ontología regional" para dar cuenta en el análisis político de los supuestos de un enfoque particular. Esto le permite otorgar una definición de "ontología política":

La ontología se relaciona con el ser, con lo que es, con lo que existe, con las unidades constitutivas de la realidad; la ontología política, por extensión, se relaciona con el ser político, con lo que es políticamente, con lo que existe políticamente y con las unidades que componen la realidad política (Hay, 2006: 80).

En este sentido, todo análisis político -de modo consciente o no- parte de determinados supuestos que definen el objeto de su análisis, es decir, las entidades que componen la realidad política ${ }^{1}$. ¿Qué es la política? ¿Qué elementos componen la realidad política? ¿Qué hace que algo sea político o no lo sea? ¿Existen principios que ordenen la realidad política? Son preguntas que aun cuando no sean explícitas delimitan las mismas posibilidades de análisis: si pensar en agentes o estructuras, si el sujeto orienta su acción en términos racionales o no, si existen explicaciones causales en el análisis político, etc. De hecho, sostiene Hay, las posiciones epistemológicas y metodológicas que se adopten en un análisis se derivan de los supuestos ontológicos de los cuales se parte.

La propuesta de Hay se dirige entonces a mostrar la necesidad de dar un paso más respecto de la epistemología y a señalar la relevancia de volver esto explícito. No es sino, en cierto sentido, una profundización de la necesidad de la "lógica del precedente". Donde, en un razonamiento circular, asume el supuesto ontológico de la causalidad para explicar la derivación entre dimensiones (ontología, epistemología, metodología). Aquí me interesa explorar la opción descartada por Hay, aquella que en sus términos se dedica a una reflexión abstracta sobre la naturaleza de lo existente, con un doble objetivo: de un

1. C. Hay sostiene que el precedente al respecto es Alexander Wendt y su posición en el campo de las relaciones internacional. (Wendt, 1999). 
lado, discutir el carácter "regional" de una ontología política donde, en última instancia, no se explicita qué aporta la ontología respecto de la epistemología (puesto que, p.e., también en epistemología se discuten paradigmas individualistas, holistas, estructuralistas, conductistas, etc.); de otro lado, discutir la "lógica de la derivación" ya existente en el edificio jerárquico que ordena posiciones donde la lógica y la metafísica preceden a las ciencias particulares. Avanzar entonces en una definición diferente de ontología política.

\section{Antecedente}

Si bien la relación ontología - política puede rastrearse en el largo plazo, incluso para pensar los modos en que las teorías sobre el ser se han vinculado al pensamiento político, aquí me interesa partir de un autor que le otorga una inscripción específica al problema: W. E. Connolly. Si lo tomo como punto de partida se debe a dos motivos: por un lado, porque le otorga a ese vínculo una materialidad específica al situarlo en una tradición de pensamiento; por otro lado, porque su propuesta se sitúa en una apuesta política². En am-

2. En general, existen dos referencias centrales para pensar el uso de la ontología por parte de la teoría política contemporánea. De un lado, ciertos autores señalan que surge de transformaciones históricas. Así, por ejemplo S. K. White indica que el giro ontológico surge de la modernidad tardía: "El giro ontológico al que me refiero emerge con la creciente conciencia de que vivimos en tiempos de la «modernidad tardía». El sentido de la vida en la modernidad tardía implica una mayor conciencia de la convencionalidad de gran parte de lo que se ha tomado como certeza en el mundo moderno. El reciente giro ontológico podría caracterizarse generalmente como el resultado de una creciente propensión a interrogar más cuidadosamente a aquellas "enti- bos sentidos, para Connolly pensar en términos de ontología política no es una reflexión sobre los supuestos que fundan una epistemología, sino un modo determinado de trabajar en teoría política que se opone a otros. En un texto titulado "Nada es fundamental..." utiliza la expresión "interpretación ontopolítica" para definir su perspectiva:

[...] quizás mejor utilizar "interpretación ontopolítica". Onto, porque toda interpretación política invoca un conjunto de fundamentos sobre las necesidades y las posibilidades del ser humano; sobre, por ejemplo, las formas en las que el ser humano puede estar conformado y las posibles relaciones que el ser humano puede establecer con la naturaleza. [...] Decir que algo es fundamental o que nada es fundamental, entonces, es hacer una interpretación ontopolítica. Por lo tanto, toda interpretación de los acontecimientos políticos, no importa cuán profundamente se sumerja en un contexto histórico específico o cuán grande sea el cúmulo de datos sobre

dades" presupuestas por nuestras formas típicas de ver y hacer en el mundo moderno" (White, 2000: 4). De otro lado, ciertos autores sostienen que se trata de una transformación que surge de una tradición teórica específica. Así, por ejemplo V. Paipais señala: "Este nuevo pluralismo, expresado de manera más enfática por académicos prominentes como William Connolly, David Campbell, Chantal Mouffe y Bonnie Honig, adopta abiertamente la necesidad de compromisos ontológicos en política, al mismo tiempo que reivindica la antigua prerrogativa de la filosofía política para formular afirmaciones con relevancia universal y aplicabilidad. Igualmente, entre las filas de la izquierda post-heideggeriana (Badiou, Laclau, Nancy, Rancière, Žižek), la primacía de la ontología es abiertamente reconocida y promovida como un medio para repolitizar las estructuras políticas sedimentadas y las instituciones democráticas, volviendo a movilizar las fuerzas sociales inertes para renovar el activismo político y las prácticas de resistencia al capitalismo global" (Paipais, 2017: xi). 
el que se asiente, contiene una dimensión ontopolítica (Connolly, 1995: 1).

En esta primera definición, Connolly sostiene que toda interpretación de los acontecimientos políticos, todo análisis político se puede señalar, supone una dimensión ontopolítica. De modo que lo ontológico remite a la "dimensión" de los presupuestos fundamentales que orientan una u otra interpretación. Siendo así, su posición parece cercana a la expuesta por Hay. Sin embargo, luego de establecer esta afirmación general, Connolly se pregunta por qué la discusión ontológica no ha sido objeto de análisis crítico por parte de las ciencias sociales o humanas. Y encuentra tres razones fundamentales para explicar esta falta de atención: primero, porque existe una supuesto generalizado según el cual cuando la filosofía moderna destituye la teleología aristotélica y las doctrinas de la creación cristiana ya no resulta necesario dar cuenta de un orden fundamental del mundo, es decir, las explicaciones sociales ya no necesitarían de posiciones metafísicas sobre el mundo. Segundo, recuperando la lectura histórica de $\mathrm{H}$. Blumenberg afirma que el secularismo moderno derrotó las cosmologías anteriores que le otorgaban una finalidad intrínseca a la naturaleza, esto es, el mundo sin finalidad se convirtió en algo disponible para el dominio técnico (Blumenberg, 2008). Por último, existe una posición extendida según la cual los problemas de la política, la ética o la psicología no requieren discusiones sobre los presupuestos ontológicos. El defensor por excelencia de esta última posición es J. Rawls cuando afirma que la justicia como equidad es política, no metafísica, esto es, la discusión sobre la justicia no necesita volver sobre los presupuestos ontológicos (Rawls, 2010). Ahora bien, estas tres ra- zones van a ser sintetizadas unos párrafos más adelante por Connolly con la expresión "la primacía de la epistemología":

Existe un presupuesto particular -llamémosle la primacía de la epistemología- que une a la mayoría de los científicos sociales estadounidenses, protegiéndolos de este debate. Darle primacía a la epistemología es pensar que tienes acceso a criterios de conocimiento que dejan atrás el reino de la ontología o que tu epistemología proporciona procedimientos neutrales a través de los cuales plantear y resolver cada cuestión ontológica. [...] La primacía de la epistemología produce un cortocircuito con las cuestiones ontológicas al asumir que una vez que se alcanza el procedimiento correcto para alcanzar la verdad como correspondencia, coherencia o consenso, cualquier cuestión pendiente se resolverá a través de ese método o se demostrará que es irrelevante. La primacía de la epistemología, por lo tanto, trata las ideas de sujeto, objeto, representación y conocimiento como si ya estuvieran fijadas en su ámbito de aplicación. El atractivo de esta perspectiva reside en su pretensión de eludir cuestiones que de otro modo podrían contaminar, descarrilar o confundir la confianza operativa en sí mismas de las ciencias humanas (Connolly, 1995: 5).

Las tres razones que otorga Connolly sintetizadas en la primacía de la epistemología permiten establecer un desplazamiento respecto de su afirmación inicial. Puesto que si toda interpretación parte de ciertos presupuestos ontológicos, la desatención de una reflexión explícita sobre los mismos se explica por dos razones: de un lado, por razones históricas, en cierto sentido Connolly sostiene que es una consecuencia de la modernidad -de una lectura de la misma- lo que lleva al abandono de la reflexión ontológica; de otro lado, por razones políticas, puesto que aparece Rawls, y con él cierta tradición 
liberal, para quienes la reflexión ontológica resulta innecesaria para la discusión política. No son, por cierto, motivos que puedan ser analizados por separado: en cierto sentido lo que está en juego es el formalismo que funda cierta tradición moderna de la política. Existe, en los términos de Connolly, una especie de "minimalismo ontológico" como consenso general que oblitera la problematización de los supuestos ontológicos. Por ello mismo, no se puede sostener con Hay que la ontología es simplemente el antecedente de epistemología, puesto que precisamente la misma epistemología es la que niega la necesidad de la ontología. O mejor, una definición de epistemología como el establecimiento de criterios de conocimientos que fundamentan una serie de procedimientos neutrales para dar lugar a un saber legítimo es lo que reduce la ontología a algo innecesario. Entre ontología y epistemología existe entonces una relación antagónica ${ }^{3}$.

De modo que ya es posible establecer una diferencia entre quienes afirman que la reflexión ontológica resulta innecesaria para la discusión política y aquellos que la reivindican. Por esto, el mismo Connolly inscribe su reflexión recuperando una corriente específica del pensamiento contemporáneo donde cita nombres como Nietzsche, Heidegger, Arendt, Fou-

3. De hecho, el autor que cita Connolly para dar cuenta de una concepción opuesta de verdad a la tradición epistemológica es M. Heidegger. Este es un indicio clave, pues para el pensador alemán la epistemología se entiende en el marco de la modernidad como época de la imagen del mundo (del sujeto que funda la certeza del objeto en una relación de representación), y desde esta definición se la comprende como una etapa más en la tradición metafísica que olvida la pregunta por el ser. En fin, la epistemología requiere, por definición, el olvido de la ontología. (Biset, 2020) cault, Taylor, Irigaray, Deleuze, Williams y Derrida. En muchos de estos autores la posición es exactamente la contraria: lo que más requiere de discusión son los supuestos ontológicos y esto parece negarse en el minimalismo. Para estos autores, el minimalismo ontológico no lo es de ningún modo, es decir, el formalismo que parece prescindir de la reflexión ontológica no deja de ser una ontología social discutible entre otras, cuyos presupuestos son tan sólidos como los de una cosmología finalista o un creacionismo cristiano. Por ello, se trata de dar lugar a una teoría que muestre el carácter contingente y discutible de toda ontología social sin buscar la reducción de las posiciones ontológicas a un consenso amistoso. De hecho, es la imposibilidad de un consenso, o de una relación amistosa entre ontologías opuestas, lo que le permite a Connolly redefinir el pluralismo y pensar una democracia agonística. No se trata de un formalismo que sitúa la discusión política reduciendo los presupuestos metafísicos, sino un pluralismo radical que reconoce el carácter conflictivo de los supuestos ontológicos y por ello los somete a discusión.

En este sentido, Connolly avanza en precisiones que delimitan su posición respecto de otras, no se trata simplemente de reconocer la dimensión ontológica de toda interpretación política, sino de definir los rasgos de un modo de interpretación específico. Un modo de interpretación que se dirige precisamente a discutir diferentes ontologías sociales, o mejor, a mostrar cómo toda ontología social es contingente y discutible [contingent and contestable]. Esto conlleva, para Connolly, dos estrategias: por un lado, una estrategia de desmontaje [strategy of detachment] que combina la genealogía foucaultiana y la deconstrucción derridiana para mostrar la 
contingencia de los supuestos que orientan una interpretación; por otro lado, una estrategia de montaje [strategy of attachment] como dimensión afirmativa desde la que se sostienen ciertos presupuestos sabiendo que son discutibles. La interpretación ontopolítica adquiere rasgos específicos: se inscribe en una tradición post-nietzscheana, define estrategias de trabajo con la teoría y asume una posición política definida como democracia agonística ${ }^{4}$. Ya no se trata de una reflexión general sobre presupuestos, sino de hacer del mismo trabajo teórico una discusión sobre esos presupuestos. Esta es, para Connolly, precisamente la tarea de la "crítica" actual:

La cuestión más persistente a la que se enfrenta la interpretación crítica hoy en día es la relación irónica que asume con sus propias proyecciones ontopolíticas. Debemos convertir esta condición paradójica (esta incoherencia, esta contradicción auto-referencial, esta presuposición de un estándar de verdad que nosotros mismos cuestionamos, etc., etc., etc.) en una fuerza para el pensamiento afirmativo. Esta condición/ límite de reflexión es improbable que se elimine. Este perfil ambiguo que establece los términos dentro de los cuales el pensamiento necesariamente procede, hoy constituye simultáneamente nuestra reverencia y aliciente (Connolly, 1995: 38).

4. Escribe Connolly: "El respeto agonístico es una virtud recíproca apropiada para un mundo en el que los partisanos se encuentran en intensas relaciones de interdependencia política. El agonismo es la dimensión a través de la cual cada parte mantiene un pathos de la distancia de los demás con los que está comprometido. El respeto es la dimensión a través de la cual se reconocen los límites y se establecen conexiones a través de líneas de diferencia". (Connolly, 1991: 12, cursivas del autor)

\section{Ontologías políticas}

Si la perspectiva de Connolly resulta un antecedente fundamental para pensar el vínculo entre ontología y política, me interesa recuperar aquí el modo en que tres autores recientes buscan definir el pensamiento político y realizar una lectura de una cierta tradición contemporánea. Me voy a detener en tres libros: Sustaining Affirmation. The Strengths of Weak Ontology in Political Theory de Stephen K. White (2000), A leftist ontology (2009) compilado por Carsten Strathausen, Postfoundational Political Thought (2007) de Oliver Marchart. En los tres textos, si bien atendiendo a la diversidad de posiciones, se propone una cierta aproximación a la ontología desde el pensamiento político de izquierda.

Me interesa comenzar con White porque construye su perspectiva desde una lectura atenta de Connolly. Para White se trata, por un lado, de pensar específicamente cómo se ha producido un giro ontológico en la teoría política contemporánea y, por el otro, cómo esto implica redefinir el mismo concepto de ontología. De hecho, la indagación de White se dirige a pensar cómo se puede sistematizar un concepto de ontología a partir de su uso en la teoría política. Atendiendo a que para cierta tradición en el concepto de ontología resuena el de metafísica, lo que implicaría un retroceso respecto de una modernidad cuyo logro habría sido desembarazarse de una política que suponía compromisos ontológicos demasiado fuertes. White sostiene que se trata de indagar, por el contrario, el antagonismo entre ontología y metafísica desde por lo menos tres indicios: primero, cómo la filosofía analítica de la ciencia ha mostrado que cada teo- 
ría científica presupone la existencia de ciertas entidades ontológicas; segundo, que en la modernidad tardía se trata de mostrar la contingencia de buena parte de nuestras certezas, y por ende que los compromisos ontológicos son constitutivamente históricos; tercero, que se trata de pensar en una dimensión existencial cómo articulamos el significado de nuestras vidas.

Para sistematizar su uso del concepto de ontología, o su relevancia para la teoría política, White propone diferenciar entre ontologías "fuertes" y "débiles" 5 . Con la expresión "ontologías fuertes" se refiere a cierta recuperación del concepto de ontología en el pensamiento contemporáneo, pero con demasiado compromiso metafísico en autores como Leo Strauss, Eric Voegelin o Alasdair Maclntyre. Frente a ello, propone una "ontología débil" que se enfrenta, de un lado, a la ontología fuerte $\mathrm{y}$, del otro, al pensamiento liberal:

Mi término ontología débil tiene como objetivo destacar lo que es distintivo de este nuevo fenómeno. El pensamiento que me interesa se resiste a la ontología fuerte, por un lado, y a la estrategia de gran parte del pensamiento liberal, por el otro. Este último ha ignorado o suprimido generalmente la reflexión ontológica, a veces afirmando tácitamente el yo de teflón, a veces expresando neutralidad hacia él. La ontología débil encuentra que los costos de tales estrategias superan los beneficios reclamados (White, 2000: 7).

White define cuatro características de la ontología débil. En primer lugar, la ontología débil es "fundamental y discutible", es decir, todas las concepciones del yo

5. Indudablemente White busca desplazar una posición como la de G. Vattimo que hace ya un par de décadas construyó la expresión "pensamiento débil" por la de "ontología débil". o del mundo son discutibles y al mismo tiempo necesarias. En segundo lugar, una ontología débil supone un concepto de sujeto viscoso [stickier], que no se reduce al cuestionamiento de la definición de sujeto propia de la modernidad, de un sujeto autofundado o fundamento último, sino que busca mostrar su configuración desde ciertas realidades existenciales. En tercer lugar, White señala que una ontología débil se caracteriza por el cultivo de sí [cultivation], para indicar que las figuraciones del sujeto no responden a una relación cognitiva sino estético-afectiva. En cuarto lugar, White plantea un problema central: ¿cuál es la relación entre ontología y posiciones ético-políticas? Esto es importante porque una ontología fuerte no es solo la adopción de ciertas convicciones metafísicas sobre la naturaleza del hombre, la existencia de Dios o el orden del mundo, sino dar lugar a un esquema de la derivación o deducción: derivar de ciertos supuestos ontológicos una posición ético-política. Para no volver a adoptar un esquema vertical de la derivación, White sostiene que se trata de "circuitos de reflexión, afecto y argumentación". La referencia a "circuitos" señala la necesidad de cuestionar la derivación entre ontología y política, como si de ciertos supuestos ontológicos surgiera la deducción de una política o una ética. Este es un esquema metafísico, o quizás un rasgo por excelencia de lo metafísico, que una ontología busca discutir: no se trata de derivar sino de pensar circuitos que no producen relaciones de necesidad.

En cierto sentido, Strathausen parte de las afirmaciones de White pero acentúa su relevancia para una posición de izquierda. De hecho, comienza la introducción de $A$ leftist ontology señalando que una "ontología de izquierda" se define por 
asumir el horizonte antifundacional de la ontología (distanciándose del relativismo y el fundacionalismo). Precisamente lo que hace que una ontología sea de izquierda es la creencia compartida en la maleabilidad histórica del paradójico terreno ontológico. Antifundacional, en este contexto, se entiende como la imposibilidad de un fundamento último, esencia estable o sustancia definida. Desde esta perspectiva, se comprende que no hay nada fijo o natural en un orden social, lo que posibilita cada vez su reinvención:

[...] se debe reconocer que la política actual (una vez más) ha llegado a un punto de distinción radical, y cualquier intento de examinar el espacio de lo político debe comenzar trazando los límites fundamentales en un nivel ontológico. Sin embargo, lo que está en juego no es cualquier ontología, sino una que se reconoce y piensa en su paradójico horizonte antifundacional (Strathausen, 2009: XXVI).

Para Strathausen esto implica determinar el modo de trabajo con la teoría, una ontología de izquierda redefine lo que se entiende por pensamiento desde que se encuentra siempre encarnado [embodied], esto es, que interactúa activamente con el mundo (cuestionando aquellas visiones que postulan una relación de representación pasiva entre pensamiento y mundo). Aún más, esta interacción es lo que define la filosofía política: "Ya sea en el ámbito de la política, la ciencia, o la cultura, el pensamiento siempre debe estar fundado en contextos sociales. Esto siempre importa. De otro modo, el pensamiento ya no sería adecuado a su nombre" (Strathausen, 2009: XXIX). Esta encarnación de la filosofía política es un modo de comprender el mismo conflicto entre filosofía y política (tal como es tematizado por Arendt por ejemplo), o la tensión entre creencias (subjetivas, históricas) y verdad (entendida como objetiva y sin tiempo). Este conflicto también se reproduce al interior mismo de las perspectivas inscriptas en una ontología de izquierda, donde la apuesta fundamental pasa por un modo de entender el conflicto. Una teoría del conflicto que no busca suprimirse, ni se lo aborda a partir de un diálogo razonable y neutral, puesto que se asume que los conflictos tienen un estatuto ontológico:

Por lo tanto, todo conflicto dentro del sistema inevitablemente se convierte en un conflicto sobre el sistema, poniendo en tela de juicio la validez histórica de los fundamentos normativos que lo constituyen. Lo que comúnmente se llama "ontología de lo político" deja de ser, por lo tanto, el terreno neutral en el cual las perspectivas de "izquierda", "centro", o "derecha" se encuentran y tratan de llegar a un acuerdo entre sí. Por el contrario, la lucha política es ontológica en el sentido de que construye la verdadera naturaleza de este terreno supuestamente neutral. No hay ontología política más allá de esta construcción. La política siempre se compromete -y trata de definir- los parámetros y las reglas del terreno sociopolítico donde diferentes creencias se encuentran entre sí. En este sentido, una ontología de izquierda reconoce que cada día la práctica política -y no sólo "lo político"- es definida por la lucha sobre la misma naturaleza de nuestro mundo y sus líneas de comunicación, sobre quién posee el derecho y el poder para delimitar sus fronteras y hacer cumplir sus reglas (Strathausen, 2009: p.

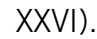

La perspectiva de Strathausen no se dirige a trabajar la ontología política como una perspectiva que reconstruye los supuestos últimos de uno u otro pensamiento político, sino que trata de asumir en qué medida una ontología puede ser de izquierda. En este sentido, en cercanía 
a la propuesta de White, su ontología política no supone una rehabilitación de fundamentos o esencias últimas, sino precisamente el debilitamiento o la ausencia de los mismos. Esta definición asume que la posibilidad de calificar a una ontología política como de izquierda surge de la misma contingencia de los fundamentos. Ahora bien, como acentúa Strathausen, pensar en términos ontológicos no lleva a pensar en un terreno neutral donde las diferentes ontologías entran en disputa, sino otorgarle al conflicto un carácter ontológico. Esto es, no solo es una ontología específica desde la contingencia de los fundamentos, sino una que asume el carácter irreductible del conflicto: no existe un terreno común dentro el cual definir posiciones políticas, sino que la disputa es la misma definición del terreno donde las posiciones se encuentran. Esto lleva, por último, a redefinir el mismo trabajo con la teoría, o en los términos utilizados: indagar de qué modo siempre un pensamiento se encuentro encarnado.

Marchart, en este recorrido, ocupa un lugar central en cuanto va a sistematizar una definición de ontología política desde un trabajo con el concepto de fundamento. Su aporte se inscribe en una doble herencia: de un lado, indica que lo que ha de denominar posfundacionalismo surge de lo que, retomando a D. Janicaud, llama heideggerianismo de izquierda (Janicaud, 2001); de otro lado, no es sino una radicalización ontológica de la categoría de antagonismo en Laclau. Vale destacar para comenzar un desplazamiento terminológico, pues para Marchart se trata de evitar el fundacionalismo como el antifundacionalismo: "[...] lo que llegó a denominarse posfundacionalismo no debería confundirse con antifundacionalismo. Lo que distingue el primero del segundo es que no supone la ausencia de cualquier fundamento; lo que sí supone es la ausencia de un fundamento último, dado que solamente sobre la base de esa ausencia los fundamentos (en plural) son posibles" (Marchart, 2009: 29). Se trata entonces, como afirma un famoso texto de J. Butler, no de la falta de fundamentos sino de su carácter contingente (Butler, 2001). Ahora bien, si se afirma no la ausencia de fundamentos, sino su contingencia, la estabilización o institución de un fundamento no se produce sino mediante un proceso político. Se trata de lo político como instancia de institución de fundamentos precarios o parciales. Es este debilitamiento de la noción de fundamento lo que vuelve a la ontología eminentemente política:

Sólo en raras ocasiones se comprende que un enfoque posfundacional de los problemas filosóficos acarrea consecuencias radicales, pues únicamente lo político puede intervenir como suplemento del fundamento ausente. Y ello implica que cualquier ontología (posfundacional) -cualquier hauntologie será necesariamente una ontología política, la cual ya no puede ser subordinada al estatus de una región de la indagación filosófica (Marchart, 2009: 216).

Para Marchart, el posfundacionalismo afirma la naturaleza política del ser en tanto que ser, y así se comprende la necesidad de reivindicar el uso del término ontología. Sin embargo, en este caso, la apuesta pasa por mostrar el carácter irreductiblemente político de la ontología y no su definición desde la izquierda. La categoría "ontología política" no remite a una ontología regional entre otras, como si la referencia fuera la naturaleza o esencia de la cosa política, sino a mostrar el carácter irreductiblemente político de toda ontología. Puesto que si no existe una definición última del ser en tanto que ser, 
estabilizar una u otra definición requiere de una institución política de su sentido.

Para sistematizar su perspectiva, Marchart recupera la diferencia entre lo político y la política comprendida a la luz de la diferencia ontológica heideggeriana (en sus términos, la diferencia política "refleja" la diferencia ontológica) ${ }^{6}$. La diferencia conceptual entre lo político y la política es un índice del fundamento ausente de la sociedad. Lo político refiere al momento instituyente de la sociedad, se trata del fundamento suplementario de la dimensión infundable de la sociedad. 0 , en otros términos, debido que no existe un fundamento último de la sociedad, se dan procesos de fundación precarios. La política es la actualización de ese fundamento en ciertas formas de acción, en el subsistema político, etc. Esta diferencia resulta central en tanto divide el concepto de política entre la dimensión del fundamento ausente que siempre es suplementado por un fundamento contingente y la dimensión del sistema político o las acciones políticas. Todo el problema radica en cómo entender aquí la "diferencia", es decir, cómo es posible tematizar la relación entre lo político y la política. Es allí donde la diferencia ontológica heideggeriana permite mostrar que la distinción sólo es posible como resultado de su propia diferencia, esto es, lo político como ausencia de fundamento aparece en la política. El "momento político" es aquel en el cual en cualquier dimensión social se enfrenta la radical ausencia de fundamentos y su fijación precaria.

Esto será desarrollado en un texto posterior por Marchart, radicalizando la categoría de antagonismo. Si Heidegger es quien

6. He intentado mostrar algunos de los problemas que ha producido la esquematización de la diferencia entre lo político y la política en el pensamiento político contemporáneo. (Biset, 2011) otorga las herramientas teóricas para pensar la diferencia política, Laclau es quien va a otorgar las herramientas teóricas para pensar el carácter ontológico del antagonismo. Para Marchart, Laclau es quien muestra el doble estatuto de la noción de diferencia: por un lado, como enseñó la lingüística estructuralista el valor de una entidad surge de su relación diferencial con el resto; por otro lado, para que eso sea posible debe existir un sistema donde las diferencias puedan ser estabilizadas frente a un exterior, es esto lo que nombra el antagonismo. Dicho en otros términos, un antagonismo no es un conflicto o una diferencia entre otras, sino que es la negatividad que permite la estabilización de un fundamento contingente:

El término "antagonismo" denota este momento de doble cara: el momento de la institución originaria así como el momento de la destitución originaria del orden social. [...] Sugiero que es aquí, en su ontología política, donde debe situarse el logro decisivo de Laclau. La sociedad se instituye políticamente, y ser instituido políticamente significa ser instituido a través del trabajo de lo negativo, es decir, del antagonismo. Puesto que la ontología es la ciencia del ser-qua-ser, podemos designar esta afirmación como ontológica en el sentido de que constituye una reivindicación sobre la naturaleza antagónica del ser social como tal, y no simplemente sobre la naturaleza de los asuntos políticos en el sentido estricto de la política como una esfera o forma de acción particular. Si se toma en serio, esta ontología conducirá a un dramático cambio de perspectiva. El mundo social comienza a aparecer bajo una luz fuertemente política. Como consecuencia, la teoría del antagonismo de Laclau puede redirigir nuestra atención a la naturaleza fundamentalmente disputada, conflictiva y dislocada de todo lo social (Marchart, 2018: 23). 
Según señala Marchart se trata de pasar de la categoría de ontología política como algo regional a la de ontología de lo político, esto es, el carácter político del serqua-ser. Ahora bien, esto redefine aquello que se entiende por teoría, ya no como un ejercicio académico, sino como el repliegue de la política sobre la filosofía. Esta perspectiva se aleja de cualquier visión contemplativa de la filosofía, puesto que el pensamiento no es sino un modo de tramitar el antagonismo en la misma tradición.

Si he recuperado las perspectivas de White, Strathausen y Marchart, en la herencia de Connolly, es porque dan cuenta de la ontología en el campo específico de la teoría política. En los casos analizados se abandona definitivamente aquella definición de ontología como un trabajo neutral sobre supuestos últimos, para delimitar un modo de trabajo específico en el campo de la teoría política. Me interesa recuperar tres indicios de las perspectivas analizadas. El primer indicio es la necesidad de rehabilitar la discusión ontológica en el campo del pensamiento político de izquierda. Esto conlleva una doble diferencia: frente a una tradición liberal que entiende que la discusión política debe evitar discutir fundamentos últimos o posiciones sustantivas y frente a una tradición metafísica que en la rehabilitación de la ontología termina por establecer fundamentos últimos. Una tradición de izquierda en este campo se enfrenta a una tradición liberal y a una tradición conservadora. El segundo indicio es el reconocimiento del carácter contingente de los fundamentos, que se piensa en dos registros a su vez: como reconocimiento de un momento histórico específico, pero también como una apuesta política que busca desestabilizar cualquier fijación de esencias últimas. El tercer indicio se encuentra en el estatuto central del agonismo o del antagonismo, que en Connolly y White aparece como el carácter disputable de todo fundamento, y en Marchart y Strathausen aparece como el antagonismo irreductible en la fijación de un terreno que permite estabilizar posiciones contingentes.

El uso de la expresión "ontología política" en teoría política es entonces un modo de redefinir aquello que se entiende por trabajo con la teoría. Como señala Connolly, no es un trabajo complementario a la epistemología, sino una apuesta contra la primacía de la epistemología para definir lo qué es trabajar con la teoría. Esto lleva en muchos casos a abandonar el uso de palabras como teoría y/o filosofía: se trata de "pensamiento". En este sentido, pensamiento se opone a la teoría como la delimitación de categorías que se aplican a un objeto, es un modo de preguntar que hace del antagonismo su mismo proceder. No es un pensamiento sobre el antagonismo, pues pensar es antagonizar en tanto procede a desestabilizar los fundamentos que hacen que algo sea y lo ordena según determinadas categorías (los modos de ser). En estos autores, esto no es sino un modo de tramitar la herencia del pensamiento francés de la década del 60 (un pensamiento postnietzscheano para Connolly, un pensamiento postheideggeriano para Marchart) donde se produce un desplazamiento del giro lingüístico al giro ontológico. Ahora bien, este mismo giro va a tener importantes implicancias en otras disciplinas como la antropología - los estudios sobre ciencia y tecnología contemporáneos. Donde va a aparecer con fuerza la expresión "políticas ontológicas" para mostrar, específicamente, 
que la cuestión política se ubica en la misma constitución de un mundo ${ }^{7}$.

\section{Políticas ontológicas}

En el campo de la antropología la expresión "giro ontológico" ha sido utilizada para circunscribir una serie de teorías donde la ontología adquiere un estatuto central. Existen dos modos de delimitar este giro: de un lado, una perspectiva amplia que reconstruye diversas corrientes donde la relación con las alteridades deja de pensarse como representación cultural para indagar cómo se definen los existentes. En este sentido, es una crítica a cierto constructivismo social (que a veces adquiere la forma del multiculturalismo) y una revisión de ciertas dicotomías centrales en el modo de clasificar los existentes. Así, por ejemplo, F. Tola. y A. Dos Santos ordenan las posiciones en el giro ontológico en antropología en función de divisiones geográficas: una tradición surgida en América del Sur (cuyo referente central es E. Viveiros de Castro), una tradición francesa (cuyos nombres centrales serían B. Latour, P. Descola e I. Stengers) y una tradición norteamericana (cuyos nombres centrales serían A. Escobar, M. Blaser y M. de la Cadena) (Dos Santos y Tola, 2016) ${ }^{8}$. De otro lado, una perspecti-

7. Esto ha producido una redefinición de lo que se denomina "International Political Thought", puesto que permite pensar la misma multiplicidad de mundos en el mundo. (Prozorov, 2013).

8. Vale destacar que autores como M. Blaser y M. de la Cadena utilizan la expresión "ontología política" para pensar diversos conflictos en América Latina. Escribe Blaser: "Esta noción de ontología, donde la multiplicidad ontológica, las ontologías múltiples y la performatividad de los relatos se entrelazan entre sí, constituye la base del proyecto de una ontología política. El término «ontología polí- va restringida que sistematiza el giro ontológico como una propuesta metodológica en antropología que permite generar un nuevo modo de trabajo. M. Holbraad y M. A. Pedersen en su libro Ontological turn (2017) dan lugar a una sistematización que se circunscribe al aporte de tres autores: E. Viveiros de Castro, R. Wagner y M. Strathern, incluso señalando que este giro se diferencia de otros usos de la ontología en antropología como los de Latour o Descola (Holbraad y Pedersen, 2017).

Como puede observarse, ambas perspectivas le otorgan un lugar central a $\mathrm{E}$. Viveiros de Castro, incluso algunas reconstrucciones ubican a una conferencia que dictó en 1998 titulada "And" como el punto de partida del giro ontológico (Viveiros de Castro, 1998). Más allá de las discusiones sobre qué autores incluir o excluir, se puede señalar que es un cierto campo de problematizaciones que en el mismo trabajo antropológico vuelve a plantear la pregunta por el modo en que se definen y clasifican los existentes. Esto ha permitido, primero, revisar ciertas dicotomías como la que oponen naturaleza - cultura y/o humano - nohumano que han servido para diferenciar modos de existencia y otorgarle diferentes atributos (lo que cuestiona la existencia de una realidad única y una diversidad de representaciones en torno a ella, es decir, una concepción según la cual existe una naturaleza a la que tienen acceso privilegiado las ciencias y una pluralidad de culturas compuestas por discursos, representaciones o construcciones sociales) ${ }^{9}$.

tica» implica simultáneamente una cierta sensibilidad política, un campo de problemas y una modalidad de análisis o crítica". (Blaser, 2013: 24).

9. Indudablemente el cuestionamiento a la división entre naturaleza y cultura en vistas de nuevos materialismos, posiciones posthumanistas u ontologías hibridas resulta central en todo este debate. 
Segundo, esta misma revisión, problematiza una noción de cultura que genera un modo de trabajo donde las diferencias son representaciones culturales de la misma realidad (y que algunos vinculan al "giro lingüístico" o a cierta predominancia de los análisis centrados exclusivamente en el discurso). Tercero, esto ha posibilitado una serie de discusiones políticas sobre la multiplicidad de mundos que existen en el mundo, o mejor, sobre los diferentes modos de componer mundos incorporando a existentes no-humanos (teniendo una incidencia central en el campo de los debates sobre el antropoceno).

Para lo que interesa aquí, la cuestión es cómo esta discusión sobre qué es lo que existe y cómo se definen los múltiples modos de existencia resulta relevante para el pensamiento político. Como he señalado, lo que está en juego en el giro ontológico es una cuestión metodológica que desplaza la pregunta sobre "cómo ver mejor" a la pregunta "qué hay que ver". Con ello se indica que la mirada del antropólogo no está constituida sólo por presupuestos sociales, políticos o culturales, sino por compromisos sobre lo que son las cosas $^{10}$. Frente a ello, es necesario abrir una

De hecho, una referencia central aquí es el libro de P. Descola Más allá de naturaleza y cultura, donde precisamente se trata de trabajar desde diferentes ontologías. En este libro, P. Descola define ontología como "sistemas de propiedades de los existentes, que sirven de punto de anclaje a formas contrastadas de cosmologías, modelos de lazo social y teorías de la identidad y la alteridad". (Descola, 2012, 190). Es a partir de esta definición que distingue cuatro ontologías (animismo, naturalismo, totemismo y analogismo), indicando que la división naturaleza-cultura sólo se entiende dentro de la ontología naturalista.

10. Esto aparece claramente cuando Holbraad discute que "ontología" sea otro nombre para "cultura". (Holbraad, 2011) perspectiva que pueda dar cuenta de la pluralidad de modos de ser, esto es, de la forma en que algo puede ser determinado como un ser. Para Holbraad y Pedersen se trata ante todo de una cuestión metodológica: indagar el modo en el que se pueden ver las cosas en el propio material etnográfico, es decir, preguntar ante todo "qué" hay que ver, revisando los compromisos ontológicos sobre lo que son las cosas y lo que podrían ser. Esto se sintetiza en la expresión según la cual no es lo mismo pensar diferente sobre las mismas cosas que tener diferentes cosas sobre las que pensar. La antropología entonces es un lugar privilegiado para la ontología en tanto el encuentro con la alteridad permite revisar nuestros propios supuestos ontológicos. Qué existentes que cuentan en cada mundo es aquello que debe volverse contingente para un trabajo etnográfico que asume el giro ontológico.

En un texto colectivo, Viveiros de Castro, Holbraad y Pedersen (2014) abordan la relación entre ontología y política señalando que existen tres modos de vincular ambos términos: un modo filosófico, donde la política se deriva de una ontología que describe cómo son las cosas; un modo sociológico, donde la desacreditación de los proyectos ontológicos conduce a pensar cómo deberían ser las cosas y un modo antropológico que afirmando la multiplicidad de los modos de existencia intenta pensar cómo las cosas podrían ser, esto es, como pueden ser "de otro modo" [otherwise]. Escriben:

Por lo tanto, aunque el giro ontológico en antropología ha hecho del estudio de la diferencia etnográfica o "alteridad" una de sus marcas, está menos interesado en las diferencias entre las cosas que dentro de ellas: la política de la ontología es la pregunta acerca de cómo las personas y las 
cosas podrían diferir de sí mismas (...). La ontología, tal y como la entendemos desde la antropología, es la deducción trascendental comparativa, etnográficamente fundada, del Ser (el oxímoron es deliberado) tal y como difiere de sí mismo® en otras palabras, el ser-como-otro como inmanente al ser-como-sí. La antropología de la ontología es la antropología como ontología区 no la comparación de ontologías, sino la comparación como ontología (Holbraad, Pedersen y Viveiros de Castro, 2014).

Se trata entonces de mostrar cómo el giro ontológico hace de la misma antropología -de su método- una política. Y esto porque hace del pensamiento un modo de diferir, asumiendo que "diferir es en sí mismo un acto político". El giro ontológico vuelve política la antropología de modo inmanente porque la convierte en un modo de hacer experimental que inscribe la misma diferencia en su proceder, es una producción de diferencia o alteridad que sostiene indefinidamente lo posible como potencia, como lo que podría ser.

En un campo cercano de problemas, aunque no idéntico, existe una tradición vinculada a la Action-Network Theory que también va a trabajar el vínculo ontología y política desde cierta antropología. A. Mol usa la expresión "política ontológica" para señalar que las condiciones de lo real no están dadas, que la realidad no es algo que preceda a las prácticas que le dan origen, por ello el término política permite comprender este proceso de modelación de la realidad, y así su carácter abierto y discutible. Por ende se trata de mostrar cómo la realidad es hecha, y como tal es localizada histórica y culturalmente. Esto conlleva el paso del singular ontología a ontologías: las ontologías son siempre múltiples (no plurales). Ahora bien, para Mol se trata de diferenciar esta perspec- tiva de dos posiciones: el perspectivismo y el constructivismo. En el caso del perspectivismo se asume que la realidad es una, que lo que existe es único y puede ser mirado desde diferentes perspectivas. Esto multiplica las perspectivas pero la realidad sigue siendo única. En el caso del constructivismo se asume que diversas versiones de la realidad fueron construidas, que si bien ha existido una pluralidad de las mismas, una resulta triunfante y se impuso. En ambos casos, perspectivismo o constructivismo, el centro recae en la pluralidad, y no en la multiplicidad:

Hablar de la realidad como múltiple depende de otro conjunto de metáforas. No las de perspectiva y construcción, sino los de intervención y perfomance. Estos sugieren una realidad que se hace y es performada [enacted] y no es observada ${ }^{11}$. En lugar de ser vista por una variedad de miradas mientras permanecen intactos en el centro, la realidad se manipula por medio de diversos instrumentos en el transcurso de una variedad de prácticas (Mol, 1999: 77).

De modo que la referencia al sintagma "política ontológica" viene a indicar la performatividad de lo real, lo que no significa simplemente que lo que es sea el resultado de una serie de decisiones $u$ opciones tomadas de modo consciente (se opone al constructivismo). Por el con-

11. Existe un problema de traducción de difícil resolución en esta cita, pues en inglés "enactment" se aproxima a "perfomance" y específicamente en este texto se usan alternativamente. En textos posteriores, A. Mol utiliza exclusivamente el término "enact" para diferenciar su perspectiva de cierto uso extendido del término "performance" en las ciencias sociales. Resulta difícil encontrar un término español que reúna todos los significados del inglés "enact" y una traducción literal como realizan algunos como "enactar" resulta extraña al español. En fin, he decidido atendiendo a esta salvedad utilizar el término "performar" 
trario, el concepto de performatividad permite comprender el carácter artificial de la realidad pero no remitida a una pluralidad de opciones que pueden ser elegidas de modo simple. En sus estudios inscriptos en el ámbito de la medicina, Mol muestra que no se trata de diferentes perspectivas sobre la misma enfermedad o de la construcción de diversos relatos al respecto, sino de prácticas que performan de un modo u otro tal enfermedad. En el sentido de que las prácticas médicas como la clínica, la estadística o la patofisiología la conforman de diferentes modos, y entre estos múltiples modos de hacer de la enfermedad una realidad existen relaciones, es decir, se producen "interferencias"12.

La posición de Mol se inscribe en algunos de los avances de la Action-Network Theory, que tiene como uno de sus autores centrales a B. Latour. Y esto debido a que desde sus investigaciones pioneras en el ámbito de la ciencia preguntando ¿qué sucede en los lugares en lo que se hace ciencia?, muestra que la ciencia surge de una serie de relaciones pragmáticas que se dan en el laboratorio. La ciencia surge de una red heterogénea de relaciones, pero esto puede ser extendido más

12. En un texto dedicado al problema del método, J. Law recupera la propuesta de Mol para indicar que todo método es performativo, es decir, ayuda a producir realidades, y por ende nunca puede ser una cuestión meramente técnica, pues se juega allí la pregunta sobre cómo es posible hacer las cosas de modo diferente. En este libro, Law define a la política ontológica del siguiente modo: [...] si las realidades se performan [enacted], entonces la realidad no es en principio fija o singular, y la verdad ya no es el único motivo para aceptar o rechazar una representación. Esto implica que hay varias razones posibles, incluida la política, para un tipo de realidad en lugar de otra, y que estos motivos pueden en cierta medida debatirse. Esta es una política ontológica (Law, 2004: 162). allá de la ciencia. Lo que cada cosa es no surge de una cualidad esencial sino de las relaciones que mantiene con otras cosas. Pero es una red que actúa, y que por ende redefine la noción de agencia, esto es, lo que es surge de un conjunto de relaciones que producen lo real. El giro propuesto por esta concepción rompe con una noción de agencia asentada sólo en un sujeto humano, para abordar un principio de simetría generalizada entre naturaleza y cultura (Latour, 2007). Latour defiende, en este sentido, un "realismo constructivista" según el cual lo que existe depende de la red que lo describe.

En este marco general, Latour cuando expande su concepción más allá de una visión constructivista de la ciencia, mostrando el carácter performativo de cada realidad, da lugar a una "ontología de la multiplicidad": se trata de pensar en los términos de pluriversos o cosmopolíticas. Ya en su clásico Nunca fuimos modernos, Latour desarrolla lo que denomina "constitución moderna" donde lo moderno designa dos prácticas diferentes: una serie de prácticas que crean híbridos de naturaleza y cultura y una serie de práctica de purificación que crean dos zonas ontológicas distintas, la de los humanos y la de los no-humanos. Desde esta definición de lo moderno, Latour apuesta por una antropología simétrica donde las cosas y los hombres tienen el mismo estatuto en redes híbridas. Ahora bien, desde este principio de simetría generalizada la diversidad no puede ser entendida como distintos juegos de lenguaje, puesto que se haría del ser una entidad prefabricada estable que puede ser nombrada de diversos modos. De este modo se reintroduciría el gran divisor entre naturaleza y cultura, entre humano y no-humano, en la división entre lenguaje y ser. Por el con- 
trario, Latour plantea una ontología procesual que tiene a la "mediación" como categoría central. Como señala su libro Investigación sobre los modos de existencia:

El objetivo será obtener menos diversidad en el lenguaje -habrá que pagar en moneda y no en bonos- pero más diversidad en los seres admitidos a la existencia -hay más de una categoría o, más precisamente, la voluntad de saber no es la única categoría que permite interrogar la diversidad del ser (pasaremos mucho tiempo quitando esa dificultad del camino) (Latour, 2013: 35).

Esta cita da cuenta de cómo el proyecto de Latour de una antropología simétrica se convierte en una investigación ontológica sobre los modos de existencia que apuesta por el pluralismo. En este sentido, hay una diversidad de existentes híbridos que en la conformación de una red se convierten en actantes. Esa simetría puede ser traducida en lo que se ha denominado una "ontología plana" donde los diversos existentes tienen el mismo estatuto, o mejor, los existentes son activos, relacionales y requieren de traducción en una realidad que es siempre procesual ${ }^{13}$. Esta necesidad de traducción es lo que dará lugar a una expresión como "parlamento de las cosas", es decir, a la necesidad de una diplomacia no restringida al ámbito de lo humano. Para Latour se trata de dejar la oposición entre humanidad y naturaleza, para pensar en los términos de un pluriverso entendido como un ensamblaje que se compone lentamente. Esto desactiva la oposición entre lo construido y lo no construido, pues todo lo es, para pensar en lo que está bien o mal construido, y así introduce una indagación política sobre la

13. El término "ontología plana" remite a los trabajos de Manuel De Landa (De Landa, 2002). composición. Se trata de la posibilidad de encontrar un común:

$\mathrm{Y}$, sin embargo, los dos manifiestos tienen algo en común, a saber, la búsqueda de lo Común. La sed por un Mundo Común es lo que hay de comunismo en el composicionismo, con esta pequeña pero crucial diferencia: que tiene que ser compuesto lentamente en lugar de darse por sentado e imponerlo a todos. Todo sucede como si la raza humana estuviera de nuevo en movimiento, expulsada de una utopía, la de la economía, y en búsqueda de otra, la de la ecología. Dos interpretaciones diferentes de una pequeña raíz pequeña, oikos, la primera siendo una distopía y la segunda una promesa que todavía nadie sabe cómo cumplir. ¿Cómo puede ser construido un "hogar" habitable y respirable para esas masas errantes? Ésa es la única pregunta que vale la pena hacer en este Manifiesto composicionista (Latour, 2015).

En un sentido cercano, I. Stengers acentúa la noción de "cosmopolítica" para explorar la posibilidad de un mundo en común a partir de relaciones entre entidades heterogéneas. Es una "exploración performativa" que busca articular las entidades que componen el mundo siempre abierta a lo posible y desconocido. Piensa en los términos de ontologías múltiples en cuanto busca abordar la ontología política del mundo como composición de prácticas de conocimiento y compromisos ético-políticos. Se produce así una ontologización de la actividad política puesto que se busca descentrar y abrir el mundo que cada uno habita, donde el desafío es cómo pensar una "asamblea", o quizá componerla, que reúna ensamblajes heterogéneos. Stengers destaca que la propuesta cosmopolítica no busca decir lo que es ni lo que debe ser sino hacer pensar. Y esto porque la palabra "cosmos" que aparece 
allí designa lo desconocido de los mundos múltiples y cómo se pueden producir articulaciones que no conduzcan a una paz transcendental, esto es, que no eliminen su heterogeneidad o divergencia. La pregunta de la cosmopolítica es cómo pueden entenderse colectivamente en tanto agenciamiento aquellos que constituyen un mundo heterogéneo:

La cosa no es dirigirse a ellos, sino disponer [agencer] el conjunto, de tal manera que el pensamiento colectivo se construya "en presencia" de quienes hacen existir su insistencia. Darle un nombre a esta instancia, cosmos, inventar la manera en que la "política", que es nuestra firma, pudiese hacer existir su "doblez cósmica", las repercusiones de lo que se va a decidir, de lo que construye sus razones legítimas, sobre lo que se mantiene sordo a esta legitimidad, eso es la propuesta cosmopolítica (Stengers, 2014: 23).

Para pensar esta cosmopolítica, Stengers señala que se trata de pensar la inseparabilidad del modo propio de un ser (su ethos) y el hábitat de ese ser (su oikos) para dar lugar a ese murmullo excluido por los saberes. Pero no para ampliar aquello que se considera ciencia o saber legítimo, sino para pensar algo como una "asamblea" de los mundos divergentes. La cuestión es cómo pensar el modo y el hábitat para posibilitar lo heterogéneo evitando la descomposición de fuerzas indiferentes y la composición armónica. En resumen, indica Stengers, abrir la posibilidad para que el "murmullo del idiota" tenga respuesta:

[...] cómo, mediante qué artificios, mediante qué procedimientos, ralentizar la ecología política, conferirle una eficacia al murmullo del idiota, a este "hay algo más importante" tan fácil de ignorar debido a que no es posible "tomarlo en cuenta", debido a que el idiota no propone nada que "cuente". La cuestión es "eto-ecológica": qué oikos puede darle lugar a la emergencia de aquello que será capaz de "hacer importar" lo que no puede imponerse en la cuenta (Stengers, 2014: 33).

Esta reconstrucción no busca desconocer la diversidad de posiciones, las discusiones, los conflictos que existen dentro del giro ontológico en antropología así como al interior de la Action-Network Theory. Sólo me interesa destacar, de un lado, cómo aparece con fuerza la reflexión ontológica en el campo de la antropología, produciendo una serie de desplazamientos teóricos y metodológicos con estrechos vínculos con algunas de las cuestiones abordadas aquí. De otro lado, no resulta menor que en estas preguntas ontológicas sea central la cuestión política. Con diferentes acentos, utilizan la expresión "política ontológica" para abordar cómo las cosas pueden diferir de sí mismas o cómo la realidad es performada. Si el problema de la alteridad, del otro, es constitutivo de la antropología, aquí se radicaliza ya no sólo para pensar una alteridad más allá de las fronteras epistemológicas, sino para abordar la posibilidad de ontologías múltiples o la composición de un común.

\section{Ontología política deconstructiva}

El recorrido propuesto se ha dirigido, ante todo, a proponer una cartografía inicial para avanzar en una definición de ontología política. El punto de partida fue la definición general propuesta por Hay según la cual los supuestos ontológicos son precedentes a las perspectivas epistemológicas. Sin embargo, esta definición conlleva por lo menos dos problemas ya señalados: de 
un lado, en su pretensión de generalidad no puede dejar de partir de un supuesto ontológico tal como el principio de causalidad en una lógica jerárquica; de otro lado, esa misma generalidad dificulta la posibilidad de diferenciar aquellas posiciones que destacan la centralidad de la ontología para la política de aquellas que la niegan. Por estos motivos, he avanzado en la reconstrucción de dos tradiciones cuya convergencia permite delimitar una definición más específica.

Antes de precisar esta definición, ubicar como antecedente la categoría de "interpretación ontopolítica" de Connolly permitió no sólo señalar algunos elementos que muestran por qué la cuestión ontológica fue obliterada en las ciencias sociales y las humanidades, sino establecer como rasgo general la "primacía de la epistemología" en tanto clausura de la cuestión ontológica. Esto resulta central en tanto una perspectiva ontológica no es simplemente la indagación sobre los supuestos que fundan las diversas posiciones epistemológicas, puesto que la primacía de la epistemología es la que imposibilita avanzar en la pregunta ontológica. Epistemología y ontología son antagónicas en este sentido. Y lo son porque el establecimiento de la epistemología como fundamento de las ciencias supone la negación de la necesidad de plantear cuestiones ontológicas: establecer la legitimidad de los criterios de cientificidad y una serie de reglas metodológicas es suficiente. Esto mismo es lo que permite señalar la segunda diferencia establecida por Connolly: frente a aquella tradición, Ilamada "liberal" en muchas ocasiones, que sostiene que la discusión política no se dirige a cuestiones ontológicas o metafísicas, esto es, se trata de supuestos sobre los que no resulta necesario discutir en tanto el diálogo político debe posibilitar avanzar en acuerdos incluso con supuestos metafísicos antagónicos.

Desde la primera tradición reconstruida, aquella que va de White a Marchart, la categoría de "ontología política" se dirige a precisar un modo específico de trabajo en el pensamiento político. Los diversos autores señalan no sólo que la cuestión ontológica es por definición discutible (frente a su negación), sino que precisamente la imposibilidad de partir de fundamentos últimos es lo que permite señalar que toda ontología es política. Dado que no es posible otorgar una definición última de los fundamentos, existe una institución política en la estabilización de unos u otros fundamentos. Para esta perspectiva precisamente la tarea del pensamiento contemporáneo es mostrar el carácter contingente de los fundamentos y señalar que ese es el lugar por excelencia de los antagonismos políticos. Entiendo que esta primera perspectiva puede sintetizarse como: la exigencia que la cuestión política le plantea a la ontología.

Desde la segunda tradición reconstruida, aquella que va de Viveiros de Castro a Stengers, la categoría de "políticas ontológicas" se dirige a precisar un modo específico de trabajo en el campo de la antropología. No resulta menor que la discusión se ubique en este campo, puesto que la cuestión es analizar cómo las diferencias no se reducen a una diversidad cultural sino que siempre está en juego un modo de definir lo existente y sus modos. Con diferentes acentos, y con importantes disputas, cada uno muestra que la cuestión central es "qué es lo que existe", es decir, las entidades que cuentan para cada mundo. Este desplazamiento permite mostrar cómo ciertas divisiones o clasificaciones son supuestas una y otra 
vez: las diferencias naturaleza/cultura y no-humano/humano. Lo que permite avanzar en una discusión política más allá de esas divisiones, una política de los diversos existentes: los múltiples mundos en el mundo. Entiendo que esta segunda perspectiva puede sintetizarse como: la exigencia que la cuestión ontológica le plantea a la política.

Desde mi perspectiva, la ontología política se entiende como el doble movimiento entre una redefinición de la política y una redefinición de la ontología, es decir, como contaminación diferencial entre las dos tradicionales trabajadas ${ }^{14}$. ¿Qué significa esto? Atender a cómo los lenguajes políticos contaminan la perspectiva ontológica y atender a cómo los lenguajes ontológicos contaminan la perspectiva política: existe un repliegue entre ontologías políticas y políticas ontológicas. Primero, el repliegue de la ontología sobre la política significa por lo menos dos cosas: por una parte, que el pensamiento político

14. La expresión "contaminación diferencial" la recupero de la lectura que Derrida realiza de Benjamin. Allí la utiliza para deconstruir la oposición entre las diversas violencias en Benjamin: "No hay, pues, oposición rigurosa entre la fundación y la conservación, tan sólo lo que yo llamaría (y que Benjamin no nombra) una contaminación diferenzial (différantielle) entre las dos, con todas las paradojas que eso puede inducir. [...] La desconstrucción es también el pensamiento de esa contaminación diferenzial, y el pensamiento atrapado en la necesidad de esa contaminación" (Derrida, 2008: 98). Es posible señalar que es una expresión que permite entender la categoría de "différance" como cuestionamiento de una tradición analítica donde la diferente se da entre elementos indivisibles que tienen límites claros y distintos unos de otros. Frente a ello, la tradición deconstructiva es una problematización de la $d i$ visibilidad de los límites, no para negarlos, sino precisamente para indagar su partición y porosidad constitutiva. no es una referencia a un campo determinado, sino que constituye mediante preguntas aquello que es o no es político; por otra parte, que las preguntas políticas por excelencia son "qué" es que algo sea y "cómo" sea. Segundo, el repliegue de la política sobre la ontología significa por lo menos dos cosas: por un lado, que los lenguajes políticos adquieren un estatuto trascendental; por otro lado, que si existe contaminación entre dos dimensiones es porque no hay identificación, esto es, porque existe un desfasaje entre política y ontología: existen procesos de politización y despolitización que trabajan en la misma diferencia entre ambas dimensiones.

¿Qué es una ontología política? El repliegue entre pensar lo político a través de la exigencia de la cuestión ontológica y pensar lo ontológico a través de la exigencia de la cuestión política ${ }^{15}$. En esta definición se encuentra el doble movimiento que propongo para pensar una definición posible de ontología política que avance sobre dos problemas recurrentes en las tradiciones reconstruidas: desatender a los problemas que trae la categoría de ontología y a los problemas que trae la categoría de política. O para decirlo en otros términos: sucede como si el acento en la expresión "ontología política" no permitiera atender a las múltiples dimensiones inscriptas allí.

¿Qué significa desatender a las implicancias de la categoría de ontología? Mi impresión es que ciertos usos del

15. Como señala Abbott, no se trata sólo de insistir en la contingencia de los conceptos ontológicos ni de suponer que esto daría lugar a una política concreta, sino de "pensar lo político a través de la exigencia de la cuestión ontológica". Recuperando esta expresión entiendo que se puede responder a la pregunta de este artículo. (Abbott, 2014). 
término ontología hacen de la ontología una afirmación sobre el mundo, el debilitamiento de los fundamentos parece ser una especie de descripción de la contemporaneidad y terminan por convertir a la diferencia ontológica en un problema de relación. Frente a ello, entiendo que la ontología es un problema de método de pensamiento que pregunta cómo es posible la formulación de la pregunta por el ser. Antes de dar una definición de ser o de los modos de ser, me interesa recuperar aquella indicación según la cual es necesario atender a cómo es posible formular la pregunta por el ser. Incluso más, la indicación metodológica es que la ontología no es sino un pensamiento de lo trascendental -del a prioriy que la pregunta se dirige a que algo sea y cómo sea ${ }^{16}$. Esto puede ser pensando en términos negativos: si lo que es no resulta inmediato, que algo sea y cómo sea no puede ser sino una indagación sobre la categoría de ser y las divisiones desde las cuales se clasifican modos de ser. Esto

16. Esto lo he trabajado en el artículo "Metódica de la ontología política" (Biset, 2018). No resulta menor que una corriente central del pensamiento político de izquierda heredero de Althusser inscriba la pregunta ontológica en la política, o mejor, modulen está pregunta sobre la posibilidad de exceder la ontología misma. A. Badiou, J. Rancière y E. Balibar en nociones como ser y acontecimiento, partición de lo sensible o ser y mal-ser, cómo el orden del ser encuentra siempre un exceso. Incluso más, es precisamente ese exceso el lugar por excelencia de la política, sea el acontecimiento, sea aquello que no cuenta, sea el malestar del sujeto. Como he intentado señalar, no es sino esta la pregunta que modula una ontología política: las condiciones cuasi-trascendentales que hacen que algo sea (y por ende algo no sea) y cómo sea. He allí una partición, una diferencia, o mejor, el polemos irreductible de la misma diferencia ontológica. Cf. (Badiou, 1999), (Rancière, 1996) y (Balibar, 2014). implica por lo menos dos cosas: un acento particular en el método como una búsqueda en la formulación de un preguntar y una cierta diferenciación allí. En otros términos: no hay ontología, hay ontologías en plural.

¿Qué significa desatender las implicancias de la categoría de política? Mi impresión es que en muchos casos la política adquiere un sentido vago asociado a la contingencia, es decir, se parte de la contingencia de los fundamentos para señalar que de eso se sigue que todo fundamento, definición de ser o división de modos de ser, es instituido políticamente. En este caso, política se asocia a un sentido general de institución. Ahora bien, con ello se oblitera las condiciones de formulación de la pregunta política. Pregunta política que remite a una tradición de discurso variada, compleja, conflictiva y a una realidad política que constituye las mismas posibilidades de enunciación. Como han señalado en diversas oportunidades quienes se ocupan de la historia de los lenguajes políticos, no existe un concepto de política estable y definitivo: existen una diversidad de lenguajes en disputa para definir política. Esto implica que pensar el carácter político de la ontología es empezar a diferenciar entre los lenguajes que pueden definir esa política. No hay política, hay políticas en plural.

Estos dos aspectos me permiten señalar lo siguiente: una de las tareas del pensamiento actual es avanzar en la diferenciación interna a las categorías de ontología y política. Si el sintagma "ontología política" da lugar a una reconfiguración del pensamiento contemporáneo, es necesario avanzar en una indagación que muestre los múltiples modos en qué puede ser entendido. Existen diversas ontologías políticas: un vínculo específico entre una 
definición de ontología y una definición de política. Entiendo que este vínculo que, como he insistido, no puede adquirir las formas de una derivación o de una causa, adquiere una forma particular si se lo entiende como "inscripción". Una forma política se inscribe en una ontología y una forma ontológica se inscribe en una política. Esto permite señalar, recuperando las tradiciones teóricas presentadas, que se trata de pensar la inscripción como la dinámica que establece la implicancia recíproca de las ontologías políticas con las políticas ontológicas. Redefinición de una figura de pensamiento en la problematización de la partición ontológica del mundo.

¿Qué significa redefinir una figura de pensamiento en la problematización de la partición ontológica del mundo? Significa que una ontología, en su estatuto trascendental, es una figura de pensamiento que se asienta en lo dado mismo para preguntar por su modo de ser. Un modo de pensar que, de un lado, le otorga al pensamiento un estatuto que excede la mera representación de lo existente, pues el pensamiento abre algo nuevo, pero, de otro lado, esto supone siempre una relación con condiciones singulares de existencia, con el modo de configuración de un mundo determinado. Al inscribir una pregunta trascendental el pensamiento deja ser episteme representativa para constituir una zona de problematización, es decir, empieza con una pausa que indaga a qué se le otorga existencia y a qué no y cómo se diferencia entre los modos de existencia. Este repliegue no es del mundo, cada mundo siempre es una existencia dada, sino que es en el mundo más allá del mundo: trascendental. Una ontología política es la formulación de una pregunta trascendental sobre los límites de lo existente, es decir, señala que la pri- mera pregunta política es por la existencia o inexistencia.

Sin embargo, allí el uso del término política no puede entenderse sólo como desestabilización, u operación de volver contingentes delimitaciones prexistentes, puesto que en tal caso se partiría de una definición dada de política en un mundo para replegarla sobre la misma vacilación de los límites de ese mundo. Toda vacilación tiene un carácter abismal. Este abismo, siempre tramado de silencio (o de los límites de todo lenguaje), no es un simple vacío. Dicho de otro modo, la calificación de político de un pensamiento se produce desde su contaminación con lenguajes políticos específicos, siempre múltiples, pero, segundo, la misma posibilidad de apertura de un pensamiento conlleva un doble desfasaje: al interior de los lenguajes políticos y de la pregunta respecto a ellos. Entiendo que esta perspectiva desplaza el acento, ya no se encuentra la fuerza de una reflexión ontológica en un socavamiento de la noción de fundamento sino en la reformulación de una figura de pensamiento que politiza la partición ontológica del mundo.

En resumidas cuentas, he intentado establecer dos indicaciones preliminares. Primero, me parece importante volver sobre lo siguiente: pensar en términos ontológicos no es un cambio de ropa simple donde se pasa de la legitimidad científica de la teoría al qué y el cómo de lo existente, pues resulta imprescindible dar cuenta, por un lado, de la noción de ser con la que se trabaja y, por el otro, de los problemas de método que supone esta indagación. Dicho de otro modo, no resulta simple la transferencia de la ontología a otros dominios porque conlleva un repliegue, antes que preguntar por el ser de tal cosa surgen dos cuestiones: qué se 
entiende por ser y cómo es posible realizar esa pregunta. Se puede decir de otro modo, si la pregunta ontológica es la indagación trascendental sobre qué algo sea y cómo sea, supone trabajar con atención la categoría de ser y los modos de formular una pregunta sobre ello. Segundo, resulta imprescindible precisar en qué sentido se utiliza el término política. En muchas ocasiones, parece que se diluye su sentido en una especie de sinonimia generalizada respecto de contingencia, performatividad o institución. Como si se dijera, dado que el mundo no es algo dado sino performado, existe política allí. Se trata de una disolución que es también un gesto de despolitización. No se trata, por cierto, de volver a una definición excesivamente restringida, puesto que la diseminación del sentido del concepto de política es uno de los desafíos contemporáneos. Aun así, entiendo que resulta imprescindible un trabajo sobre eso que he denominado "lenguajes políticos": existe una extensa historia que articula prácticas políticas, conceptos políticos y teorías políticas que producen una sedimentación de sentidos sobre la que resulta necesario trabajar. La cuestión pasa por evitar un doble gesto de negación de la política: una delimitación de su sentido cuya especificidad termine siendo muy restrictiva y una expansión que la diluya en una totalidad vacua. Como se sabe, nada más despolitizante que afirmar que todo es político (donde ya no existe nada por politizar).

Si la partición ontológica del mundo en su estatuto trascendental se encuentra contaminada de historicidad, la cuestión es cómo dar lugar a un modo de preguntar que produzca una partición de la partición. Una intervención en el campo de la génesis de un mundo en tanto historicidad trascendental: un trabajo que produce una dislocación del modo de clasificar los existentes al mismo tiempo que socava una definición dada de política ${ }^{17}$. En otros términos: un desplazamiento de la multiplicidad a la diferenciación (precisamente porque la diferencia es: dinámica, polémica y contaminada). Diferenciación política en la ontología, diferenciación ontológica en la política. Su método: la pregunta. Su gesto: la partición. Su apuesta: la apertura. Por esto mismo entiendo que existe una distancia irreductible de una ontología deconstructiva respecto de un pluralismo liberal radicalizado en los términos de multiplicidad ontológica. Distancia porque inscribe una y otra una dinámica de diferenciación en el campo trascendental. Esta dinámica de diferenciación remite por lo menos a tres cuestiones: distinguir (espaciamiento), diferir (temporalización) y polemizar (politización) ${ }^{18}$. Un mundo siempre es un

17. De hecho, vale recordar que no es sino este problema del cual emerge algo así como la deconstrucción. Me estoy refiriendo específicamente a la recepción de Tran-Duc-Tao en su vinculación de materialismo dialéctico y fenomenología. En cualquier caso, la cuestión inicial para Derrida es cómo es posible pensar una historicidad trascendental, que conlleva en términos específicos articular las dos herencias referidas por TranDuc-Tao, pero con un pequeño desplazamiento, no a Husserl y Marx, sino Heidegger y Hegel. La cuestión es, en estos textos tempranos, el paso de la historicidad a la génesis, o mejor, la génesis como historicidad trascendental. Una "genealogía" deconstructiva no es sino un trabajo sobre la diferencia polémica como instancia (cuasi) trascendental.

18. Una nota central, en este sentido, surge de los múltiples sentidos de la diferencia en el pensamiento deconstructivo, donde no sólo se piensa como "distinguir" y "diferir", sino como "polemos". Dos notas centrales: primero, Derrida desde textos tempranos piensa la diferencia como polemos trascendental. Si en el seminario de 1964 escribe "le phainestai est polemos", en 
modo de declinar la partición inmanente a la diferencia. Una dinámica de diferenciación es, a la vez, la inscripción de diferencias inmanentes a un mundo y de diferencias entre mundos (o entre mundo e in-mundo). Por esto mismo, pensar en el "cómo" mismo de la diferencia modular un imposible. Nuevamente, entonces, diferencia en la misma inscripción de mundos posibles.

Todo esto para señalar, en fin, que los diversos modos de pluralismo no son la única posibilidad de las ontologías políticas contemporáneas. Todo esto para señalar, a la vez, que los diversos modos de pensar una institución infundada no son la única posibilidad de las ontologías políticas contemporáneas. Una ontología política deconstructiva es una lógica de la inscripción que habilita un pensamiento de la diferencia como partición de lo trascendental.

\section{Bibliografía}

Abbott, M. (2014) The figure of this world, Edinburgh, Edinburgh University Press.

Badiou, A. (1999) El ser y el acontecimiento, Buenos Aires, Manantial.

Balibar, E. (2014) Ciudadano-Sujeto, Buenos Aires, Prometeo, 2014.

el texto sobre la "différance" anota: "la palabra diferencia (con e) nunca ha podido remitir así a diferir como temporización ni a lo diferente como polemos. Es esta pérdida de sentido lo que debería compensar-económicamente- la palabra diferancia (con a)" (Derrida, 1994: 44). Segundo, este polemos no remite a un conflicto entre amigo y enemigo, a una diferencia ética o política, sino a la misma partición del mundo (un mundo es, cada vez, la inscripción de diferencias ontológicas).
Biset, E. y Farrán, R. (2011) Ontologías políticas, Buenos Aires, Imago Mundi.

Blaser, M. (2013) "Notes towards a political ontology of "environmental» conflicts", Green, L. (ed.). Contested Ecologies: Nature and Knowledge, Cape Town: HSRC Press, pp. 13-27.

Butler, J. (2001) "Fundamentos contingentes: el feminismo y la cuestión del "postmodernismo»", La ventana, $\mathrm{N}^{\circ} 31$, pp. 7-41.

Connolly, W. (1991) Identity|Difference, Minneapolis, University of Minnesota Press.

Connolly, W. (1995) The ethos of pluralization, Minneapolis, University of Minnesota Press.

Connolly, W. (2008) Democracy, pluralism and political theory (editado por S. Chambers y T. Carver), Abingdon and New York, Routledge.

Connolly, W. (2013) The Fragility of Things, Durham, Duke University Press.

De Landa, M. (2002) Intensive Science and Virtual Philosophy, London and New York, Continuum.

Derrida, J. (1994) Márgenes de la filosofía, Madrid, Cátedra.

Derrida, J. (2008) Fuerza de ley, Madrid, Tecnos.

Derrida, J. (2013) Heidegger: la question de l'Etre et l'Histoire, Paris, Galilée.

Descola, P. (2012) Más allá de naturaleza y cultura, Buenos Aires, Amorrortu.

Dos Santos, A. y Tola, F. (2016), "Ontologías: usos, alcances y limitaciones del concepto en antropología", AVÁ 29, pp. 71-98.

Finlayson, A. (2010) Democracy and Pluralism. The political thought of William E. Connolly, Abingdon and New York, Routledge.

Groff, R. (2013), Ontology Revisited. London-New York, Routdledge. 
Hay, C. (2006) "Political ontology", Goodin, R. y Tilly, C. The Oxford handbook of contextual political analysis, New York, Oxford University Press, pp. 78-96.

Holbraad, M. (2011) "Can the Thing Speak?", Working Papers Series \#7, Open Anthropology Cooperative Press. pp. 1-26.

Holbraad, M. (2014) "Tres provocaciones ontológicas”, Ankulegi 18, pp. 127-139.

Holbraad, M. y Pedersen, M. A. (2017) The Ontological Turn, Cambridge, Cambridge University Press.

Holbraad, M., Pedersen, M. A. y Viveiros de Castro, E. (2014). "The Politics of Ontology: Anthropological Positions", Fieldsights-Theorizing the Contemporary, Cultural Anthropology Online, January 13.

Janicaud, D. (2001) Heidegger en France, Paris, Bibliothèque Albin Michel.

Latour, B. (2008) Reensamblar lo social, Buenos Aires, Manantial.

Latour, B. (2011) "II n'y a pas de monde commun : il faut le composer", Multitudes, $N^{\circ} 45$, pp. 38-41.

Latour, B. (2012) Nunca fuimos modernos, Buenos Aires, Siglo XXI.

Latour, B. (2013) Investigación sobre los modos de existencia, Buenos Aires, Paidós.

Latour, B. (2014) "Ensayo de un «Manifiesto composicionista»", Fractal 76.

Latour, B. y Woolgar, S. (1995) La vida en el laboratorio, Madrid, Alianza.

Law, J. (2004) After Method, Abingdon and New York, Routledge.

Maniglier, P. (2016) “¿Cuántos planetas tierra?", AVÁ 29, pp. 199-216.

Marchart, O. (2009) El pensamiento político posfundacional, Buenos Aires, FCE. Mol, A. (1999) "Ontological politics. A word and some questions", The Editorial Board of The Sociological Review, pp. 74-89.
Paipais, V. (2017) "Towards a Formal Political Ontology", Contemporary Political Theory, pp. 501-531.

Paipais, V. (2017) Political Ontology and International Political Thought, London, Palgrave Macmillan.

Prozorov S. (2013) "What is the "World» in World Politics? Heidegger, Badiou and Void Universalism", Contemporary Political Theory 12(2), May, pp. 102-122.

Rancière, J. (1996) El desacuerdo, Buenos Aires, Nueva Visión.

Rawls, J. (2010) "Justicia como imparcialidad: política, no metafísica", Revista de Filosofía (México), 42 (127), pp. 11-46.

Schürmann, R. (2017) El principio de anarquía, Madrid, Arena.

Stengers, I. (2003) Cosmopolitiques 1-2, Paris, La découverte.

Stengers, I. (2014) "La propuesta cosmopolítica”, Pléyade 14, pp. 17-41.

Strathausen, C. (2009) A leftist ontology, Minneapolis, University of Minnesota Press.

Viveiros de Castro, E. (2015) "And", The relative native, Chicago, $\mathrm{Hau}, \mathrm{pp} .39-54$.

Viveiros de Castro, E. (2010) Metafísicas caníbales, Buenos Aires, Katz.

Viveiros de Castro, E. (2018) La inconstancia del alma salvaje, Buenos Aires, UNGS.

White, S. K. (2000) Sustaining Affirmation, Princeton, Princeton University Press.

Zevnik, A. (2016) Lacan, Deleuze and world politics, New York, Routledge. 